\title{
Author Correction: Prevention of CAUTIs, CLABSIs, and VAPs in Children
}

\author{
Elizabeth H. Mack, MD, MS, FAAP, FCCM ${ }^{1, *}$ \\ Christopher T. Stem, $M D^{2}$
}

\author{
Address \\ ${ }^{*}, 1$ Division of Pediatric Critical Care, Medical University of South Carolina, 135 \\ Rutledge Avenue, Charleston, SC, 29425, USA \\ Email: mackeli@musc.edu \\ ${ }^{2}$ Department of Pediatrics, Medical University of South Carolina, 135 Rutledge \\ Avenue, Charleston, SC, 29425, USA
}

Published online: 28 April 2018

(C) Springer International Publishing AG, part of Springer Nature 2018

The online version of the original article can be found at https://doi.org/10.1007/s40746-017-0094-8

Author Correction: Curr Treat Options Peds (2017)3:221-235

$$
\text { https://doi.org/10.1007/s40746-017-0094-8 }
$$

The original version of this article unfortunately contained a mistake in Tables 3, 4 and 5 captions. The captions of Tables 3, 4 and 5 should read as:

Table 3. Indwelling urinary catheter insertion bundle

Table 4 . Indwelling urinary catheter care \& maintenance bundle

Table 5. VAP prevention bundle 